\title{
PREVALENCE AND OUTCOMES OF HYPERTENSION IN PREGNANCY IN NON-METROPOLITAN AND METROPOLITAN COMMUNITIES
}

\author{
A Master's Thesis Presented \\ By \\ JESSICA KLOPPENBURG \\ Submitted to the Faculty of the \\ University of Massachusetts Graduate School of Biomedical Sciences, Worcester \\ in partial fulfillment of the requirements for the degree of \\ MASTER OF SCIENCE
}

APRIL 15, 2021

CLINICAL INVESTIGATION 
PREVALENCE AND OUTCOMES OF HYPERTENSION IN PREGNANCY IN NON-METROPOLITAN AND METROPOLITAN COMMUNITIES

A Master's Thesis Presented

By

JESSICA KLOPPENBURG

The signatures of the Master's Thesis Committee signify completion and approval as to style and content of the Thesis.

William Jesdale, $\mathrm{PhD}$, Chair of Committee

Anthony Nunes, PhD, Member of Committee

Heidi Leftwich, DO, Member of Committee

The signature of the Dean of the Graduate School of Biomedical Sciences signifies that the student has met all master's degree graduation requirements of the school.

Mary Ellen Lane PhD,

Dean of the Graduate School of Biomedical Sciences

Master of Science in Clinical Investigation

April 15, 2021 


\section{ACKNOWLEDGEMENTS}

There are many individuals within and beyond the UMMS community that have supported, encouraged, and guided me and without whom this thesis would not have been possible. In the interest of brevity, I will only name a select few here but to all that have supported me throughout this process, please know how appreciative and grateful I am. I would like to start by thanking my obstetrician/gynecologist subject matter expert and thesis research and advisory committee member, Dr. Heidi Leftwich, who encouraged me to create a project that reflected my academic passions and provided her guidance and expertise to make it possible. My thesis advisor, Dr. Tony Nunes, will forever have my unwavering gratitude for his assistance in troubleshooting the arduous task of getting my dataset in working order, as well as for being a constant resource to whom I could turn. I would like to thank my thesis and research and advisory committee chair, Dr. Bill Jesdale, for always challenging me to think like an epidemiologist and ask the difficult questions about my work, while standing at the ready to help me adapt. Both Dr. Rob Goldberg and Dr. Kate Lapane have been instrumental in helping me through the writing process, navigating classes, and generally making it through the past year. And finally, I feel so fortunate to have gotten to know my MSCI/CPHR classmates, albeit virtually, this year. They are an inspiring group of scientists, and I am so thankful for their support, feedback, perspectives, and wealth of knowledge. 


\begin{abstract}
Background: Hypertension during pregnancy is a leading cause of birthing parent mortality and adverse pregnancy outcomes. Since non-metropolitan communities face higher rates of several risk factors for hypertension in pregnancy and shortages in obstetrical services, persons residing in nonmetropolitan areas may be at increased risk for adverse outcomes compared to those living in metropolitan areas. Our study objectives were to examine by county of birthing parent residence (1) the prevalence of chronic hypertension
\end{abstract} (cHTN) and hypertensive disorders of pregnancy (HDP), and (2) the prevalence of adverse birthing parent and neonatal outcomes associated with hypertension. Methods: Using U.S. birth certificate data from 2016 to 2018, we described the prevalence of cHTN and HDP and the association of each with several birthing parent and neonatal outcomes, stratified by non-metropolitan versus metropolitan county of birthing parent residence. Multivariable Poisson regression models were used to calculate adjusted prevalence ratios for birthing parent and neonatal outcomes among individuals with $\mathrm{cHTN}$ or HDP who lived in nonmetropolitan versus metropolitan U.S. counties.

Results: The prevalence of CHTN and HDP for US live births was $2.2 \%$ and $7.4 \%$, respectively, among non-metropolitan pregnant individuals and $1.8 \%$ and $6.6 \%$, respectively, among metropolitan pregnant individuals. After adjusting for several sociodemographic characteristics among those with HDP, the prevalence ratio for an APGAR score $<7$ at 5 minutes (aPR 1.34, 95\% $\mathrm{Cl} 1.29-1.38$ ) and 
neonatal death (aPR 1.36, 95\% Cl 1.15-1.62) was increased among offspring born to women who resided in non-metropolitan counties. Similar results were seen among those with cHTN.

Conclusion: The prevalence of cHTN and HDP is modestly more prevalent in non-metropolitan areas, but most pregnancy outcomes were similar among those residing in non-metropolitan areas compared to metropolitan areas. Further research should investigate the robustness of these findings using alternate definitions of rural and urban areas and the possible link between low APGAR score, low NICU admission, and neonatal death in non-metropolitan counties. 


\section{TABLE OF CONTENTS}

\section{Front Matter}

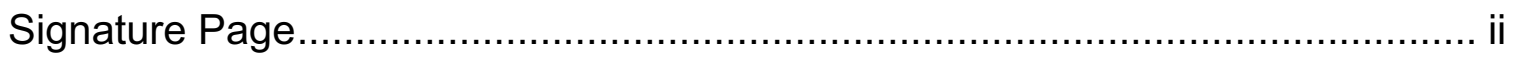

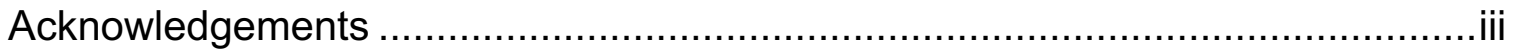

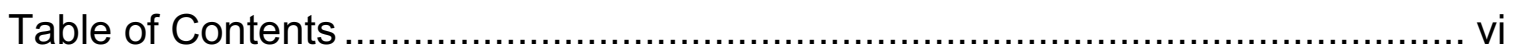

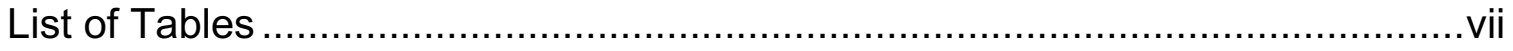

\section{Body Matter}

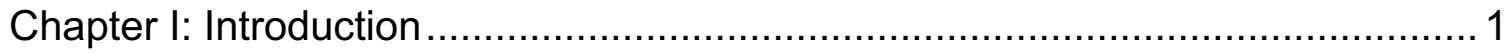

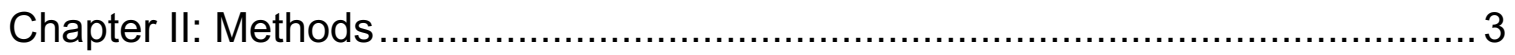

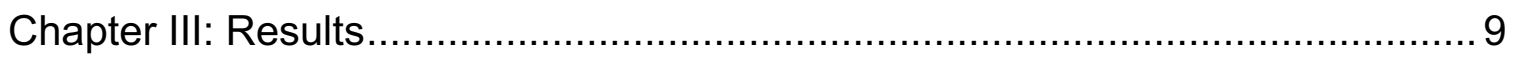

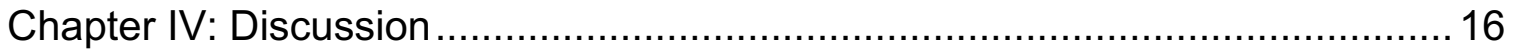

\section{Back Matter}

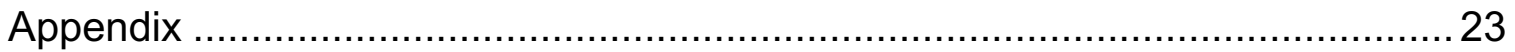

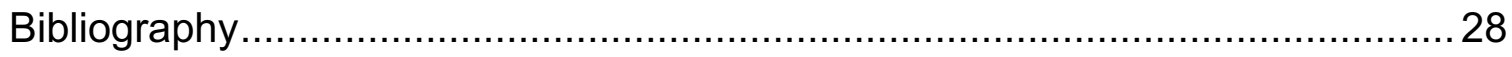




\section{LIST OF TABLES}

Table 3.1: Birthing parent Characteristics of US Live Births Complicated by Hypertension According to County of Birthing parent Residence

Table 3.2: Prevalence of Hypertension in Pregnancy Among Pregnant Individuals Residing in Metropolitan and Non-Metropolitan Counties, 2016-2018

Table 3.3: Prevalence of Adverse Birthing parent and Neonatal Outcomes among Individuals with Hypertension in Pregnancy According to Birthing parent

Residence

Table 3.4 Prevalence Ratio of Adverse Birthing parent and Neonatal Outcomes among Individuals with Hypertension in Pregnancy According to Birthing parent

Residence

Table S1: Birthing parent Characteristics of All US Live Births According to County of Birthing parent Residence

Table S2: Prevalence of Adverse Birthing parent and Neonatal Outcomes among Individuals with Hypertension in Pregnancy According to Rural-Urban Continuum Code (RUCC) .23

Table S3: Prevalence of Hypertension in Pregnancy Sensitivity Analysis .26

Table S4: Prevalence Ratios for Adverse Pregnancy Outcomes Sensitivity Analysis 


\section{CHAPTER I: INTRODUCTION}

Hypertensive disorders of pregnancy encompass gestational hypertension, pre-eclampsia, and eclampsia. These conditions are relatively common, complicating 1 in every 9 hospital deliveries in the US between 2005 and 2014. ${ }^{1}$ Hypertensive disorders of pregnancy are one of the leading causes of birthing parent mortality worldwide ${ }^{2,3}$ and are associated with an increased rate of cesarean delivery, placental abruption, disseminated intravascular coagulation, stroke, pulmonary edema, and renal failure..$^{1,2,4,5}$ These disorders have also been shown to increase the risk of intrauterine growth restriction, premature birth, and intrauterine fetal demise..$^{2,6,7}$ These adverse neonatal outcomes can have both short-term sequelae, such as respiratory distress syndrome and necrotizing enterocolitis, and long-term sequelae, including an increased risk of developing type 2 diabetes mellitus and hypertension as adults. ${ }^{6,8}$ While chronic hypertension, defined as high blood pressure diagnosed prior to pregnancy or at less than 20 weeks gestation, is less common than the hypertensive disorders of pregnancy, it similarly increases the risk of these adverse birthing parent and neonatal outcomes.

Approximately 1 in every 6 American women live in non-metropolitan areas. ${ }^{9}$ Compared with those residing in metropolitan areas, non-metropolitan residents have a greater frequency of numerous risk factors for hypertension in pregnancy including elevated body mass index, diabetes mellitus, chronic hypertension, tobacco use, poverty, and lower education level. ${ }^{9-13}$ Historically, 
persons residing in non-metropolitan areas have the highest rates of preeclampsia, but the prevalence of pre-eclampsia in metropolitan areas has been increasing at a faster rate in recent years. ${ }^{1}$ Notably, non-metropolitan areas have a shortage of obstetrical services, with over half of all non-metropolitan counties lacking an obstetric unit, and obstetrical units continue to close in disproportionate numbers in non-metropolitan areas. ${ }^{11,14-16}$ Since any form of hypertension in pregnancy typically requires management by an obstetriciangynecologist, ${ }^{17}$ persons residing in non-metropolitan areas may be at increased risk for adverse outcomes compared to those living in metropolitan areas, though little published data exists.

Using county-level data from the National Center for Health Statistics, we examined differences in the prevalence and outcomes of hypertensive disorders of pregnancy according to birthing parent residence. 


\section{CHAPTER II: METHODS}

\section{Data Source}

We conducted a cross-sectional analysis of live births in the United States using the National Center for Health Statistics (NCHS) Natality dataset for the calendar years 2016 through $2018 .{ }^{18} \mathrm{NCHS}$ Natality is a $100 \%$ sample of birth certificate data ${ }^{19}$ from all states, the District of Columbia, and the US territories. The National Vital Statistics System (NVSS) Guide for Completing the Facility Worksheets for the Certificate of Live Birth in the United States instructs facilities on how to abstract and report the birth certificate variables using medical, prenatal, and delivery records. ${ }^{20} \mathrm{~A}$ restricted-use version of the NCHS natality with county identifiers was used to calculate the prevalence of hypertension in pregnancy and associated adverse birthing parent/fetal outcomes on the basis of non-metropolitan and metropolitan county of birthing parent residence. The Institutional Review Board at the University of Massachusetts Medical School determined that this study was exempt from further review.

\section{Study Population}

All pregnant individuals who gave birth in the United States during the period January 1, 2016 - December 31, 2018 were eligible for study inclusion. A total of $11,564,457$ live births occurred during this period. Births that occurred in US territories were excluded. In addition, pregnant individuals with missing or imputed values for birthing parent age, race, ethnicity, pre-pregnancy body mass 
index (BMI), tobacco use, gestational age, pre-existing hypertension, pregnancyinduced hypertension, or eclampsia were excluded. In total, 1,512,395 records were excluded, with birthing parent race as the largest source of missingness ( $n=$ $713,179 ; 6.2 \%)$.

\section{Study Outcomes}

All study outcomes were abstracted from birthing parent medical, prenatal, and delivery records as specified in the NVSS Guide for Completing the Facility Worksheets for the Certificate of Live Birth in the United States. ${ }^{20}$ Chronic hypertension was considered to be present when pre-pregnancy hypertension was reported on the birth certificate. Since gestational hypertension and preeclampsia are not distinguished from each other in NCHS natality, they were assessed as an aggregate variable that was defined as present when pregnancyinduced hypertension was reported on the birth certificate. Eclampsia was considered to be present when eclampsia was recorded on the birth certificate. The subset of individuals with chronic hypertension who went on to develop preeclampsia in pregnancy were counted in the aggregate variable for gestational hypertension and pre-eclampsia and not counted as chronic hypertension. Those with chronic hypertension, gestational hypertension, or pre-eclampsia who developed eclampsia were included only in the eclampsia category. We created a composite variable of "any hypertensive disorder of pregnancy," which included all births in which the pregnant individual was reported to have pregnancyinduced hypertension or eclampsia on the birth certificate. 
Preterm delivery (delivery at $<37$ weeks and 0 days gestation) and cesarean delivery were defined as our principal adverse birthing parent outcomes. Gestational age at delivery was used to characterize preterm births. Gestational age in the natality dataset is reported using the obstetric estimate, except where this estimate is unavailable in which case the estimate using last menstrual period is used. Low birth weight (delivery weight $<2500$ grams regardless of gestational age at delivery), neonatal intensive care unit (NICU) admission, APGAR score less than seven at five minutes, and neonatal death were our primary neonatal adverse outcomes. Neonatal death was defined as infant not living at time of birth certificate reporting.

\section{Study Exposure}

The 2013 Rural Urban Continuum Codes (RUCC) are described in greater detail in the 2013 NCHS Urban-Rural Classification Scheme for Counties. ${ }^{21}$ In brief, RUCC 1 is a large central metropolitan area with a mean statistical area (MSA) population of 1 million or more, RUCC 2 is a large fringe metropolitan area with a MSA population of 1 million or more, RUCC 3 is a medium metropolitan area with a MSA population of $250,000-999,999, R U C C 4$ is a small metropolitan area with a MSA population of less than $250,000, R U C C 5$ is a micropolitan area with an urban cluster population of 10,000-49,999, and RUCC 6 is a noncore area with either no cluster or an urban cluster of less than 9,999 individuals. Counties with a RUCC between 1 and 4 are classified as metropolitan counties, whereas counties with a RUCC 5 or 6 are classified as 
non-metropolitan counties. Using the 2013 Rural-Urban Continuum Codes and the reported birthing parent residence county, the RUCC and corresponding metropolitan/non-metropolitan classification were assigned to each birth certificate record based on reported county of birthing parent residence..$^{22}$

\section{Study Covariates}

Birthing parent age at delivery ( $<20$ years, $20-34$ years, $\geq 35$ years), birthing parent race (American Indian or Alaska Native (AIAN), Asian, Black, white, Native Hawaiian or other Pacific Islander (NHOPI), multi-racial), ethnicity (Hispanic, non-Hispanic), pre-pregnancy BMI $\left(<18.5 \mathrm{~kg} / \mathrm{m}^{2}, 18.5-24.9 \mathrm{~kg} / \mathrm{m}^{2}\right.$, $25.0-29.9 \mathrm{~kg} / \mathrm{m}^{2}, \geq 30.0 \mathrm{~kg} / \mathrm{m}^{2}$ ), formal education (high school/GED not completed, high school/GED completed, some college or higher), insurance (private, government, other, self-pay, other), and tobacco use (>1 cigarette per day in the 3 months prior to pregnancy, $>1$ cigarette per day in any trimester of pregnancy, no tobacco use) were treated as categorical variables. Region of birth (Northeast, South, Midwest, or West) was assigned based on census tract regions. ${ }^{23}$ Pregnancy weight gain category (inappropriately low, appropriate, or inappropriately high) was assigned using the American College of Obstetricians and Gynecologists (ACOG) recommendations for pregnancy weight gain based on pre-pregnancy BMI and single/multiple gestation. ${ }^{24}$ 


\section{Statistical Analysis}

We report the distribution of birthing parent demographics and characteristics of the study population overall and among the subset of individuals with hypertension in pregnancy. We calculated the prevalence of chronic hypertension, aggregate gestational hypertension and pre-eclampsia, eclampsia, and any hypertensive disorder of pregnancy. In order to examine the occurrence of adverse birthing parent and neonatal outcomes among individuals with hypertension in pregnancy in relation to birthing parent residence, we calculated the prevalence, prevalence ratio (PR), and adjusted prevalence ratio (aPR) for preterm delivery, cesarean delivery, low birth weight, APGAR score $<7$ at 5 minutes, NICU admission, and neonatal death stratified by non-metropolitan and metropolitan birthing parent residence. A modified Poisson regression model with robust standard error was used to calculate each of the unadjusted and adjusted prevalence ratios, given that Poisson regression models are preferred over logistic regression models for cross-sectional studies with not rare outcomes. ${ }^{25,} 26$ Any demographic or clinical variable with more than a $5 \%$ absolute difference between non-metropolitan and metropolitan pregnant individuals was included in the initial regression model. The final multivariable adjusted model used to calculate adjusted prevalence ratios included birthing parent age, pre-pregnancy $\mathrm{BMI}$, birthing parent race/ethnicity, whether the individual smoked before or during pregnancy, and insurance type. In order to better account for the potential impact of excluding those pregnant individuals with missing or imputed values for 
adverse pregnancy outcomes and key sociodemographic characteristics, we conducted a sensitivity analysis where only those pregnant individuals with missing data on hypertension status in pregnancy were excluded. All statistical analyses were performed in Stata/MP (16.1) and Microsoft Excel. 


\section{CHAPTER III: RESULTS}

\section{Study Population Characteristics}

There were a total of $9,880,689$ eligible pregnant individuals and $10,052,063$ eligible live births during the study period. The median age of the study sample was 29 years (IQR $25-33$ years), $73.9 \%$ were white, 98.3\% were singleton pregnancies, and the majority of births were by metropolitan-residing pregnant individuals $(\mathrm{N}=8,485,100,85.9 \%)$.

The demographic characteristics and risk factors for chronic hypertension and the hypertensive disorders of pregnancy differed by birthing parent residence (Table 1). Pregnant individuals with hypertension in pregnancy who resided in non-metropolitan areas were more likely to be white, on Medicaid, receiving WIC during pregnancy, and a tobacco user compared with individuals who lived in metropolitan areas.

Prevalence of hypertension in pregnancy and associated adverse birthing parent/neonatal outcomes according to county of birthing parent residence

There were a total of 852,109 pregnant individuals with any form of hypertension in pregnancy ( $8.6 \%$ of total sample), and 880,765 neonates were born to mothers with hypertension in pregnancy. Approximately 67 in every 1000 births was complicated by a hypertensive disorder of pregnancy and 19 in every 1000 births was complicated by chronic hypertension. Both chronic hypertension and the aggregate variable of gestational hypertension and pre-eclampsia were 
modestly more prevalent in non-metropolitan residing pregnant individuals (Table 2).

Among the subset of births complicated by hypertension, the principal birthing parent and neonatal adverse outcomes under study were similar between nonmetropolitan and metropolitan groups (Table 3). The prevalence of adverse outcomes remained similar when further analyzed by RUCC code (Supplementary Table 2). Notably, the metropolitan group had modestly elevated prevalence of low birth weight and NICU admission, which resulted in a higher prevalence of any adverse neonatal outcome. Similar results were observed using a Poisson regression model to estimate the prevalence ratio of adverse birthing parent and neonatal outcomes among individuals with hypertension in pregnancy (Table 4).

After adjusting for birthing parent age, pre-pregnancy BMI, race/ethnicity, whether the pregnant individual smoked before or during pregnancy, and insurance type, the offspring of pregnant individuals with any hypertensive disorder of pregnancy who lived in non-metropolitan areas had an increased prevalence of APGAR score $<7$ at 5 minutes (aPR 1.34, 95\% $\mathrm{Cl} 1.29-1.38$ ) and were more likely to have died ( $\mathrm{aPR} 1.36,95 \% \mathrm{Cl} 1.15-1.62)$ compared to those residing in metropolitan areas. Low APGAR score and neonatal death were similarly elevated among those neonates born to pregnant individuals with chronic hypertension who resided in non-metropolitan areas compared with 
metropolitan areas (APGAR - aPR: 1.37, 95\% Cl 1.30-1.45; neonatal death aPR $1.32,95 \% \mathrm{Cl} 1.07-1.64)$.

\section{Sensitivity Analysis}

In the sensitivity analysis where only pregnant individuals with missing data on hypertension status in pregnancy were excluded, very similar results were seen in the prevalence of hypertension in pregnancy (Table S3), the prevalence of adverse pregnancy outcomes, and in the prevalence ratios for adverse pregnancy outcomes (Table S4). The most notable difference was seen in the prevalence ratio for neonatal death both among those with any hypertensive disorder of pregnancy, in which the prevalence ratio decreased to $1.09(95 \% \mathrm{Cl} 0.94-1.26)$ in the sensitivity analysis from $1.18(95 \% \mathrm{Cl} 1.00-1.40)$ in the main analysis, and among those with chronic hypertension, in which the prevalence ratio decreased to $1.04(95 \% \mathrm{Cl} 0.88-1.24)$ in the sensitivity analysis from1.20 (95\% $\mathrm{Cl} 0.98-1.48)$ in the main analysis. The adjusted prevalence ratio for neonatal death had a similar decrease in magnitude as the unadjusted prevalence ratio, however the direction of effect was preserved in both those with any hypertensive disorder of pregnancy and those with chronic hypertension in pregnancy. 
Table 3.1: Birthing Parent Characteristics of US Live Births Complicated by Hypertension According to County of Birthing Parent Residence

\begin{tabular}{|c|c|c|c|c|}
\hline \multirow[b]{3}{*}{ Total } & \multicolumn{2}{|c|}{ Non-Metropolitan } & \multicolumn{2}{|c|}{ Metropolitan } \\
\hline & $\mathrm{n}$ & $\%$ & $\mathrm{n}$ & $\%$ \\
\hline & 132,834 & & 719,275 & \\
\hline \multicolumn{5}{|l|}{ Year } \\
\hline 2016 & 41,389 & 31.2 & 223,490 & 31.1 \\
\hline 2017 & 44,085 & 33.2 & 237,971 & 33.1 \\
\hline 2018 & 47,360 & 35.7 & 257,814 & 35.8 \\
\hline \multicolumn{5}{|l|}{ Region } \\
\hline Northeast & 9,752 & 7.3 & 112,005 & 15.6 \\
\hline Midwest & 43,131 & 32.5 & 168,158 & 23.4 \\
\hline South & 62,935 & 47.4 & 289,689 & 40.3 \\
\hline West & 17,016 & 12.8 & 149,423 & 20.8 \\
\hline \multicolumn{5}{|l|}{ Age } \\
\hline$<20$ years & 8,582 & 6.5 & 30,903 & 4.3 \\
\hline 20-34 years & 104,280 & 78.5 & 524,586 & 72.9 \\
\hline$\geq 35$ years & 19,972 & 15.0 & 163,786 & 22.8 \\
\hline \multicolumn{5}{|l|}{ Race/Ethnicity } \\
\hline Non-Hispanic White & 99,928 & 75.2 & 385,815 & 53.6 \\
\hline $\begin{array}{l}\text { Non-Hispanic Black or African American } \\
\text { Non-Hispanic American Indian or Alaska }\end{array}$ & 15,563 & 11.7 & 159,338 & 22.2 \\
\hline Native & 4,507 & 3.4 & 4,508 & 0.6 \\
\hline $\begin{array}{l}\text { Non-Hispanic Asian } \\
\text { Non-Hispanic Native Hawaiian or Pacific }\end{array}$ & 818 & 0.6 & 31,958 & 4.4 \\
\hline Islander & 161 & 0.1 & 1,929 & 0.3 \\
\hline Non-Hispanic more than one race & 2,658 & 2.0 & 17,499 & 2.4 \\
\hline Hispanic & 9,199 & 6.9 & 118,228 & 16.4 \\
\hline \multicolumn{4}{|l|}{$\begin{array}{l}\text { Pre-Pregnancy BMI } \\
<18.5 \mathrm{~kg} / \mathrm{m}^{2}\end{array}$} & 1.4 \\
\hline $18.5-24.9 \mathrm{~kg} / \mathrm{m}^{2}$ & 27,560 & 20.7 & 183,567 & 25.5 \\
\hline $25.0-29.9 \mathrm{~kg} / \mathrm{m}^{2}$ & 30,344 & 22.8 & 181,922 & 25.3 \\
\hline$\geq 30.0 \mathrm{~kg} / \mathrm{m}^{2}$ & 73,245 & 55.1 & 343,805 & 47.8 \\
\hline \multicolumn{5}{|l|}{ Pregnancy Weight Gain } \\
\hline Appropriate & 31,138 & 23.4 & 180,857 & 25.1 \\
\hline Inappropriately high & 75,534 & 56.9 & 403,081 & 56.0 \\
\hline \multicolumn{5}{|l|}{ Education } \\
\hline High school/GED not completed & 14,195 & 10.7 & 73,435 & 10.2 \\
\hline High school/GED completed & 41,301 & 31.1 & 177,572 & 24.7 \\
\hline
\end{tabular}




\begin{tabular}{lrrrr} 
Some college or higher & 77,338 & 58.2 & 468,268 & 65.1 \\
\hline Insurance & & & & \\
Private insurance & 62,161 & 46.8 & 383,586 & 53.3 \\
Government insurance & 65,818 & 49.5 & 308,928 & 42.9 \\
Self-Pay & 2,678 & 2.0 & 14,659 & 2.0 \\
Other & 2,177 & 1.6 & 12,102 & 1.7 \\
\hline WIC & & & & \\
WIC used in pregnancy & 60,903 & 45.8 & 260,367 & 36.2 \\
\hline Diabetes & & & & \\
Pre-Pregnancy Diabetes Mellitus & 5,014 & 3.8 & 23,788 & 3.3 \\
Gestational Diabetes Mellitus & 16,096 & 12.1 & 89,129 & 12.4 \\
\hline Parity & & & & \\
Nulliparous & 61,854 & 46.6 & 346,343 & 48.2 \\
Multifetal gestation & 3,790 & 2.9 & 24,505 & 3.4 \\
\hline Fertility & & & & \\
Any infertility treatment used & 2,298 & 1.7 & 22,299 & 3.1 \\
$\quad$ Fertility Enhancing Drugs & 1,234 & 0.9 & 9,052 & 1.3 \\
$\quad$ Assisted reproductive technology & 1,019 & 0.8 & 13,455 & 1.9 \\
\hline Tobacco Use & & & & \\
Smoked cigarettes pre-pregnancy & 23,036 & 17.3 & 65,605 & 9.1 \\
Smoked cigarettes in pregnancy & 17,789 & 13.4 & 47,169 & 6.6 \\
Smoked cigarettes before or during & & & & \\
pregnancy & 23,300 & 17.5 & 66,513 & 9.2 \\
\hline Prenatal Care & & & & \\
No prenatal care & 74,970 & 56.4 & 394,554 & 54.9 \\
\hline Prenatal care initiated late & & & & \\
\hline Marital Status & 1.0 & 8,893 & 1.2 \\
Married & 18.2 & 132,204 & 18.4 \\
\hline
\end{tabular}

Table 3.2: Prevalence of Hypertension in Pregnancy Among Pregnant Individuals Residing in Metropolitan and Non-Metropolitan Counties, 20162018

\begin{tabular}{lrrrrr}
\hline & \multicolumn{2}{c}{ Non-Metropolitan } & & \multicolumn{2}{c}{ Metropolitan } \\
\cline { 2 - 3 } \cline { 5 - 6 } & \multicolumn{1}{c}{$\mathrm{n}$} & $\%$ & & $\mathrm{n}$ & $\%$ \\
\cline { 2 - 3 } \cline { 5 - 6 } Any Hypertensive Disorder of Pregnancy & 102,765 & 7.4 & & 563,640 & 6.6 \\
Gestational Hypertension or Pre-Eclampsia & 99,154 & 7.1 & & 546,442 & 6.4 \\
Eclampsia & 4,409 & 0.3 & & 20,727 & 0.2 \\
Chronic Hypertension & 30,069 & 2.2 & & 155,635 & 1.8 \\
\hline
\end{tabular}


Table 3.3: Prevalence of Adverse Birthing Parent and Neonatal Outcomes among Individuals with Hypertension in Pregnancy According to Birthing Parent Residence

\begin{tabular}{|c|c|c|c|c|c|}
\hline \multirow{6}{*}{$\begin{array}{l}\text { Any } \\
\text { Hypertensive } \\
\text { Disorder of } \\
\text { Pregnancy }\end{array}$} & \multirow[b]{3}{*}{ Total Births } & \multicolumn{2}{|c|}{ Non-metropolitan } & \multicolumn{2}{|c|}{ Metropolitan } \\
\hline & & $\mathrm{n}$ & $\%$ & $\mathrm{n}$ & $\%$ \\
\hline & & \multicolumn{2}{|l|}{105,915} & \multicolumn{2}{|l|}{584,113} \\
\hline & \multicolumn{5}{|l|}{ Birthing Parent Adverse Outcomes } \\
\hline & Cesarean delivery & 45,120 & 43.91 & 243,411 & 43.19 \\
\hline & Preterm delivery ${ }^{\S}$ & 22,875 & 22.26 & 125,134 & 22.20 \\
\hline & \multicolumn{5}{|l|}{ Neonatal Adverse Outcomes } \\
\hline & Any adverse neonatal outcome & 27,263 & 25.74 & 165,528 & 28.34 \\
\hline & Low birth weight ${ }^{*}$ & 19,194 & 18.12 & 113,707 & 19.47 \\
\hline & APGAR $<7$ at $5 \mathrm{~min}$ & 4,490 & 4.24 & 18,731 & 3.21 \\
\hline & NICU admission & 16,743 & 15.81 & 114,913 & 19.67 \\
\hline & Neonatal death & 171 & 0.16 & 797 & 0.14 \\
\hline \multirow{10}{*}{$\begin{array}{l}\text { Chronic } \\
\text { Hypertension }\end{array}$} & Total Births & 30,770 & & 159,967 & \\
\hline & \multicolumn{5}{|l|}{ Birthing Parent Adverse Outcomes } \\
\hline & Cesarean delivery & 15,541 & 51.68 & 77,314 & 49.68 \\
\hline & Preterm delivery $\S$ & 6,832 & 22.72 & 35,715 & 22.95 \\
\hline & \multicolumn{5}{|l|}{ Neonatal Adverse Outcomes } \\
\hline & Any adverse neonatal outcome & 8,080 & 26.26 & 46,359 & 28.98 \\
\hline & Low birth weight ${ }^{¥}$ & 5,391 & 17.52 & 30,736 & 19.21 \\
\hline & APGAR $<7$ at $5 \mathrm{~min}$ & 1,647 & 5.35 & 6,364 & 3.98 \\
\hline & NICU admission & 5,172 & 16.81 & 33,641 & 21.03 \\
\hline & Neonatal death & 111 & 0.36 & 479 & 0.30 \\
\hline
\end{tabular}

$\S$ Gestational age at delivery $<37$ weeks and 0 days

* Birthweight $<2500$ grams 
Table 3.4 Prevalence Ratio of Adverse Birthing Parent and Neonatal Outcomes among Individuals with Hypertension in Pregnancy According to Birthing parent Residence

\begin{tabular}{|c|c|c|c|c|}
\hline \multicolumn{5}{|c|}{ Any Hypertensive Disorder of Pregnancy } \\
\hline & PR & $95 \% \mathrm{Cl}$ & $\mathrm{aPR}^{\dagger}$ & $95 \% \mathrm{Cl}$ \\
\hline \multicolumn{5}{|c|}{ Birthing Parent Adverse Outcomes } \\
\hline Cesarean delivery & 1.02 & $(1.01-1.02)$ & 1.05 & $(1.04-1.06)$ \\
\hline Preterm birth (<37 0/7 weeks) & 1.00 & $(0.99-1.02)$ & 1.08 & $(1.07-1.09)$ \\
\hline \multicolumn{5}{|l|}{ Neonatal Adverse Outcomes } \\
\hline Any adverse neonatal outcome & 0.91 & $(0.90-0.92)$ & 0.98 & $(0.97-0.99)$ \\
\hline Low birth weight $(<2500 \mathrm{~g})$ & 0.93 & $(0.92-0.94)$ & 1.06 & $(1.04-1.07)$ \\
\hline APGAR $<7$ at $5 \mathrm{~min}$ & 1.32 & $(1.28-1.36)$ & 1.34 & $(1.29-1.38)$ \\
\hline NICU admission & 0.80 & $(0.79-0.82)$ & 0.85 & $(0.84-0.86)$ \\
\hline Neonatal death & 1.18 & $(1.00-1.40)$ & 1.36 & $(1.15-1.62)$ \\
\hline \multicolumn{5}{|c|}{ Chronic Hypertension } \\
\hline & $\mathrm{PR}$ & $95 \% \mathrm{Cl}$ & $\mathrm{aPR}^{\dagger}$ & $95 \% \mathrm{Cl}$ \\
\hline \multicolumn{5}{|c|}{ Birthing Parent Adverse Outcomes } \\
\hline Cesarean delivery & 1.04 & $(1.03-1.05)$ & 1.05 & $(1.04-1.06)$ \\
\hline Preterm birth (<37 0/7 weeks) & 0.99 & $(0.97-1.01)$ & 1.06 & $(1.04-1.09)$ \\
\hline \multicolumn{5}{|l|}{ Neonatal Adverse Outcomes } \\
\hline Any adverse neonatal outcome & 0.91 & $(0.89-0.92)$ & 0.96 & $(0.94-0.98)$ \\
\hline Low birth weight $(<2500 \mathrm{~g})$ & 0.91 & $(0.89-0.94)$ & 1.02 & $(0.99-1.05)$ \\
\hline $\mathrm{APGAR}<7$ at $5 \mathrm{~min}$ & 1.35 & $(1.28-1.42)$ & 1.37 & $(1.30-1.45)$ \\
\hline NICU admission & 0.80 & $(0.78-0.82)$ & 0.83 & $(0.81-0.85)$ \\
\hline Neonatal death & 1.20 & $(0.98-1.48)$ & 1.32 & $(1.07-1.64)$ \\
\hline
\end{tabular}

Metropolitan births is the reference group

${ }^{\dagger}$ adjusted for birthing parent age, pre-pregnancy BMI, birthing parent race/ethnicity, smoker before or during pregnancy, and insurance type 


\section{CHAPTER IV: DISCUSSION}

In this study, the demographic differences observed among pregnant individuals residing in non-metropolitan versus metropolitan areas were similar to previously published reports, both among the subset of individuals with hypertension in pregnancy and among all pregnant individuals. The estimates found for hypertension in pregnancy continue to be slightly elevated among individuals residing in non-metropolitan areas. Notably, the prevalence of adverse pregnancy outcomes associated with hypertension were similar by metropolitan status, which may hint at adaptations non-metropolitan communities have implemented. However, even the modestly increased prevalence ratios observed for low APGAR score and neonatal death in non-metropolitan compared to metropolitan areas raise concern for the effects of obstetrical service shortages that disproportionately affect non-metropolitan areas.

Demographic differences between non-metropolitan and metropolitan births

We observed a number of differences in select sociodemographic characteristics between pregnant individuals based on birthing parent residence. In non-metropolitan areas, a greater proportion of births were to individuals who lived in the Midwest or South, were under age 20, were non-Hispanic white, were on government insurance or WIC in pregnancy, and who had a pre-pregnancy BMl greater than $30 \mathrm{~kg} / \mathrm{m}^{2}$. These findings are in line with similar reports of 
higher rates of poverty, lower education levels, higher Medicaid use, and higher rates of tobacco use among non-metropolitan women. ${ }^{11,12,27}$

The American College of Obstetrician and Gynecologists' (ACOG) practice bulletin on gestational hypertension and pre-eclampsia offers consensus expert opinion on the risk factors, management, and outcomes for hypertensive disorders of pregnancy. ${ }^{2}$ Pregnant individuals who resided in non-metropolitan areas of the US had higher prevalence of some of these risk factors, such as BMI greater than $30 \mathrm{~kg} / \mathrm{m}^{2}$, low formal educational attainment, and higher Medicaid and WIC usage serving as proxies for low socioeconomic status. However, other risk factors were more common among metropolitan-residing pregnant individuals, including nulliparity and African American race. The other major risk factors highlighted in the ACOG practice bulletin were either roughly equivalent between the two groups or unavailable in the NCHS natality data set.

Prevalence of chronic hypertension and hypertensive disorders of pregnancy in non-metropolitan and metropolitan pregnant individuals

Overall, we observed very similar proportions of births complicated by hypertension among non-metropolitan and metropolitan residing individuals. We found the combined prevalence of gestational hypertension and pre-eclampsia to be $6.7 \%$, which is consistent with other reports that estimate gestational hypertension and pre-eclampsia each complicate $2-3 \%$ of US births and have become increasingly prevalent over the last several decades. ${ }^{28-31}$ Similarly, we found $1.9 \%$ of live births were complicated by chronic hypertension, an estimate 
that matches a slowly increasing trend in chronic hypertension among pregnant individuals as well. ${ }^{32,33}$

The persistent modestly increased prevalence of gestational hypertension, pre-eclampsia, and chronic hypertension among non-metropolitan residing individuals is consistent with the most recent Health Care Cost and Utilization Project report on hospitalized deliveries that demonstrated a pronounced difference in the prevalence of pre-eclampsia between non-metropolitan and metropolitan counties in 2005 that shrunk significantly by $2014 .{ }^{1}$ However, the narrowing gap simply represents a faster rate of increase of hypertension in pregnancy among metropolitan communities rather than a plateau or decline among non-metropolitan communities as the prevalence of hypertension is also rising in non-metropolitan communities.

\section{Pregnancy outcomes among individuals with hypertension}

We observed a similar frequency of adverse birthing parent/neonatal outcomes among those with hypertension in pregnancy, according to county of birthing parent residence. This finding was unexpected given the literature on the increasing shortage of obstetrical services in non-metropolitan areas ${ }^{11,12,27,34}$ and the association of increased distance to prenatal care with low birth weight and preterm birth. ${ }^{12,34}$ Since non-metropolitan communities have been facing decreased access to hospital-based obstetric services for over a decade, it is possible that some of the adaptations advocated by changemakers in these 
communities, such as birth centers, telehealth utilization, and community outreach, ${ }^{11}, 12,34,35$ may have had a protective effect against adverse birth outcomes.

The similar rates of both no prenatal care and late prenatal care initiation that we observed among women residing in non-metropolitan and metropolitan communities may support the idea that care gaps from obstetric unit closures were filled by other services in the community. Identification of the reasons for comparatively low rates of select adverse birthing parent and neonatal outcomes in non-metropolitan communities is an important area for further investigation, as any successful innovations made by non-metropolitan communities may be adapted by other communities.

However, the implications of low APGAR score and neonatal death being elevated, even if only modestly, in non-metropolitan areas compared to metropolitan areas warrants discussion. While there are many benign reasons for a low APGAR score, including birthing parent medications and interobserver variability, it can also be the consequence of more concerning pathology. ${ }^{36}$ The lower prevalence of NICU admission in non-metropolitan areas seems reassuring at first glance but may hint at a lack of appropriate resources in non-metropolitan areas, especially when examined in the context of the elevated prevalence of low APGAR score and neonatal death in non-metropolitan areas. It is therefore important to further investigate the possible link between NICU availability, APGAR score, and neonatal death by county of birthing parent relevance. 


\section{Study strengths and limitations}

The use of a large national dataset is a major strength of this observational study. In addition, the use of birth certificate data rather than hospitalization or billing records helped capture a wider population, as studies based on hospitalization records are unable to account for home births and birthing center births.

However, there are several limitations to this study that should be emphasized in the interpretation of our study findings. Due to the variables that are available for analysis in NCHS natality, we were unable to account for a number of important adverse birthing parent outcomes associated with hypertension in pregnancy, such as pregnancy loss, stroke, or birthing parent death. In addition, we were unable to examine the prevalence of gestational hypertension and pre-eclampsia separately. Given the potential for diagnostic ambiguity between gestational hypertension and pre-eclampsia and the overlap between the risk factors and associated adverse outcomes for these conditions, however, this should not have impacted the validity of our results. While our complete case analysis likely contributed to selection bias in the study, the results of the sensitivity analysis suggest that the major effect of excluding on the basis of missing or imputed key clinical and sociodemographic characteristics was nondifferential inn nature, as similar differences were seen in both the nonmetropolitan and metropolitan estimates. In addition, though the magnitude of the adjusted prevalence ratio for neonatal death was smaller in the sensitivity 
analysis than in the main analysis, the direction of the effect was preserved, suggesting that the estimates presented in this study may be slight overestimates for neonatal death.

The most notable limitation of our study is the use of non-metropolitan and metropolitan counties to designate rural/urban areas. Given the heterogeneity of rural areas, a more focused local approach to rural and urban can sometimes address nuances that larger scale national studies obscure. ${ }^{11,34}$ We attempted to account for overly broad non-metropolitan and metropolitan categories, which lump together very differently populated and resourced areas into two large groups, by running analyses with RUCC codes as well. Future studies with a greater degree of granularity in classifying birthing parent residence may be helpful in further teasing apart adverse birthing parent and neonatal outcomes related to hypertension in pregnancy among pregnant individuals residing in different geographic settings.

\section{Conclusion}

This study of hypertension in pregnancy using US birth certificate data is consistent with other recently published literature that shows an overall trend of increasing prevalence of both chronic hypertension and the hypertensive disorders of pregnancy, but a narrowing gap in the prevalence of these disorders on the basis of non-metropolitan versus metropolitan birthing parent residence. In addition, while low APGAR score and neonatal death were more common in 
offspring born to those with hypertension in pregnancy who resided in nonmetropolitan counties, other adverse birthing parent and neonatal outcomes were equivalent or lower among those with hypertension in pregnancy who resided in non-metropolitan counties compared to those residing in metropolitan counties. It will be important for future studies to investigate whether similar results are seen when analyzing the data using other definitions of rural and urban and if there are features of prenatal or obstetric care and resources in non-metropolitan communities that help account for the elevated prevalence of low APGAR score and neonatal death observed in the context of otherwise low overall risk of adverse birthing parent and neonatal outcomes. 


\section{APPENDIX}

Table S1. Birthing Parent Characteristics of All US Live Births According to County of Birthing Parent Residence

\begin{tabular}{|c|c|c|c|c|c|c|}
\hline \multirow[b]{3}{*}{ Total } & \multicolumn{2}{|l|}{ Total } & \multicolumn{2}{|c|}{ Non-Metropolitan } & \multicolumn{2}{|c|}{ Metropolitan } \\
\hline & $\mathrm{n}$ & $\%$ & $\mathrm{n}$ & $\%$ & $\mathrm{n}$ & $\%$ \\
\hline & \multicolumn{2}{|l|}{$9,880,689$} & \multicolumn{2}{|l|}{$1,395,589$} & \multicolumn{2}{|l|}{$8,485,100$} \\
\hline \multicolumn{7}{|l|}{ Year } \\
\hline 2016 & $3,352,087$ & 33.9 & 473,318 & 33.9 & $2,878,769$ & 33.9 \\
\hline 2017 & $3,292,475$ & 33.3 & 464,275 & 33.3 & $2,828,200$ & 33.3 \\
\hline 2018 & $3,236,127$ & 32.8 & 457,996 & 32.8 & $2,778,131$ & 32.7 \\
\hline \multicolumn{7}{|l|}{ Region } \\
\hline Northeast & $1,521,096$ & 15.4 & 112,868 & 8.1 & $1,408,228$ & 16.6 \\
\hline Midwest & $2,172,461$ & 22.0 & 476,182 & 34.1 & $1,696,279$ & 20.0 \\
\hline South & $3,802,167$ & 38.5 & 605,396 & 43.4 & $3,196,771$ & 37.7 \\
\hline West & $2,384,965$ & 24.1 & 201,143 & 14.4 & $2,183,822$ & 25.7 \\
\hline \multicolumn{7}{|l|}{ Age } \\
\hline$<20$ years & 488,836 & 4.9 & 102,303 & 7.3 & 386,533 & 4.6 \\
\hline 20-34 years & $7,682,598$ & 77.8 & $1,144,444$ & 82.0 & $6,538,154$ & 77.1 \\
\hline$\geq 35$ years & $1,709,255$ & 17.3 & 148,842 & 10.7 & $1,560,413$ & 18.4 \\
\hline \multicolumn{7}{|l|}{ Race/Ethnicity } \\
\hline Non-Hispanic White & $5,498,918$ & 55.7 & $1,051,866$ & 75.4 & $4,447,052$ & 52.4 \\
\hline $\begin{array}{l}\text { Non-Hispanic Black or } \\
\text { African American }\end{array}$ & $1,457,744$ & 14.8 & 126,443 & 9.1 & $1,331,301$ & 15.7 \\
\hline $\begin{array}{l}\text { Non-Hispanic American Indian } \\
\text { or Alaska Native }\end{array}$ & 81,592 & 0.8 & 40,669 & 2.9 & 40,923 & 0.5 \\
\hline Non-Hispanic Asian & 675,032 & 6.8 & 15,567 & 1.1 & 659,465 & 7.8 \\
\hline $\begin{array}{l}\text { Non-Hispanic Native Hawaiian } \\
\text { or Pacific Islander }\end{array}$ & 23,965 & 0.2 & 2,433 & 0.2 & 21,532 & 0.3 \\
\hline More than one race & 224,498 & 2.3 & 28,700 & 2.1 & 195,798 & 2.3 \\
\hline Hispanic & $1,918,940$ & 19.4 & 129,911 & 9.3 & $1,789,029$ & 21.1 \\
\hline \multicolumn{7}{|l|}{ Pre-Pregnancy BMI } \\
\hline$<18.5 \mathrm{~kg} / \mathrm{m}^{2}$ & 334,463 & 3.4 & 46,793 & 3.4 & 287,670 & 3.4 \\
\hline $18.5-24.9 \mathrm{~kg} / \mathrm{m}^{2}$ & $4,307,505$ & 43.6 & 539,171 & 38.6 & $3,768,334$ & 44.4 \\
\hline $25.0-29.9 \mathrm{~kg} / \mathrm{m}^{2}$ & $2,568,535$ & 26.0 & 356,902 & 25.6 & $2,211,633$ & 26.1 \\
\hline$\geq 30.0 \mathrm{~kg} / \mathrm{m}^{2}$ & $2,670,186$ & 27.0 & 452,723 & 32.4 & $2,217,463$ & 26.1 \\
\hline \multicolumn{7}{|l|}{ Pregnancy Weight Gain } \\
\hline Inappropriately low & $2,157,640$ & 21.8 & 314,830 & 22.6 & $1,842,810$ & 21.7 \\
\hline Appropriate & $3,100,637$ & 31.4 & 407,370 & 29.2 & $2,693,267$ & 31.7 \\
\hline Inappropriately high & $4,524,059$ & 45.8 & 660,609 & 47.3 & $3,863,450$ & 45.5 \\
\hline
\end{tabular}




\begin{tabular}{|c|c|c|c|c|c|c|}
\hline \multicolumn{7}{|l|}{ Education } \\
\hline $\begin{array}{l}\text { High school/GED not } \\
\text { completed }\end{array}$ & $1,165,209$ & 11.8 & 200,008 & 14.3 & 965,201 & 11.4 \\
\hline High school/GED completed & $2,477,816$ & 25.1 & 438,336 & 31.4 & $2,039,480$ & 24.0 \\
\hline Some college or higher & $6,237,663$ & 63.1 & 757,245 & 54.3 & $5,480,418$ & 64.6 \\
\hline \multicolumn{7}{|l|}{ Insurance } \\
\hline Private insurance & $5,065,546$ & 51.3 & 595,967 & 42.7 & $4,469,579$ & 52.7 \\
\hline Government insurance & $4,283,139$ & 43.3 & 714,479 & 51.2 & $3,568,660$ & 42.1 \\
\hline Self-Pay & 360,118 & 3.6 & 60,043 & 4.3 & 300,075 & 3.5 \\
\hline Other & 171,886 & 1.7 & 25,100 & 1.8 & 146,786 & 1.7 \\
\hline \multicolumn{7}{|l|}{ WIC } \\
\hline WIC used in pregnancy & $3,615,955$ & 36.6 & 629,250 & 45.1 & $2,986,705$ & 35.2 \\
\hline \multicolumn{7}{|l|}{ Diabetes } \\
\hline $\begin{array}{l}\text { Pre-Pregnancy Diabetes } \\
\text { Mellitus }\end{array}$ & 87,442 & 0.9 & 14,157 & 1.0 & 73,285 & 0.9 \\
\hline Gestational Diabetes Mellitus & 619,689 & 6.3 & 83,119 & 6.0 & 536,570 & 6.3 \\
\hline \multicolumn{7}{|l|}{ Parity } \\
\hline Nulliparous & $3,838,779$ & 38.9 & 499,406 & 35.8 & $3,339,373$ & 39.4 \\
\hline Multifetal gestation & 168,984 & 1.7 & 21,981 & 1.6 & 147,003 & 1.7 \\
\hline \multicolumn{7}{|l|}{ Fertility Treatment } \\
\hline Any infertility treatment used & 166,162 & 1.7 & 13,357 & 1.0 & 152,805 & 1.8 \\
\hline Fertility Enhancing Drugs & 72,104 & 0.7 & 7,270 & 0.5 & 64,834 & 0.8 \\
\hline $\begin{array}{l}\text { Assisted reproductive } \\
\text { technology }\end{array}$ & 95,369 & 1.0 & 5,850 & 0.4 & 89,519 & 1.1 \\
\hline \multicolumn{7}{|l|}{ Tobacco Use } \\
\hline $\begin{array}{l}\text { Smoked cigarettes pre- } \\
\text { pregnancy }\end{array}$ & 923,981 & 9.4 & 265,927 & 19.1 & 658,054 & 7.8 \\
\hline $\begin{array}{l}\text { Smoked cigarettes in } \\
\text { pregnancy }\end{array}$ & 707,457 & 7.2 & 215,921 & 15.5 & 491,536 & 5.8 \\
\hline $\begin{array}{l}\text { Smoked cigarettes before or } \\
\text { during pregnancy }\end{array}$ & 936,726 & 9.5 & 269,101 & 19.3 & 667,625 & 7.9 \\
\hline \multicolumn{7}{|l|}{ Prenatal Care } \\
\hline No prenatal care & 132,022 & 1.3 & 14,951 & 1.1 & 117,071 & 1.4 \\
\hline Prenatal care initiated late & $1,969,076$ & 19.9 & 308,038 & 22.1 & $1,661,038$ & 19.6 \\
\hline \multicolumn{7}{|l|}{ Marital Status } \\
\hline Married & $5,572,738$ & 56.4 & 779,673 & 55.9 & $4,793,065$ & 56.5 \\
\hline
\end{tabular}




\section{Table S2. Prevalence of Adverse Birthing Parent and Neonatal Outcomes among Individuals with Hypertension in Pregnancy According to Rural- Urban Continuum Code (RUCC)}

\begin{tabular}{|c|c|c|c|c|c|c|c|}
\hline & \multicolumn{2}{|c|}{$\begin{array}{c}\text { Birthing parent } \\
\text { Adverse Outcomes }\end{array}$} & \multicolumn{5}{|c|}{ Neonatal Adverse Outcomes } \\
\hline & $\begin{array}{l}\text { Cesarean } \\
\text { delivery }\end{array}$ & $\begin{array}{l}\text { Preterm } \\
\text { delivery }\end{array}$ & $\begin{array}{c}\text { Any } \\
\text { neonatal } \\
\text { outcome }\end{array}$ & $\begin{array}{l}\text { Low Birth } \\
\text { Weight }\end{array}$ & $\begin{array}{c}\text { APGAR } \\
<7 \text { at } 5 \\
\text { min }\end{array}$ & $\begin{array}{l}\text { NICU } \\
\text { admission }\end{array}$ & $\begin{array}{c}\text { Neonatal } \\
\text { death }\end{array}$ \\
\hline \multicolumn{8}{|c|}{ Any Hypertensive Disorder of Pregnancy } \\
\hline \multirow[t]{2}{*}{ RUCC 1} & 84,583 & 43,619 & 60,108 & 41,527 & 6,228 & 41,996 & 266 \\
\hline & 43.4 & 22.4 & 29.8 & 20.6 & 3.1 & 20.8 & 0.1 \\
\hline \multirow[t]{2}{*}{ RUCC 2} & 67,954 & 33,480 & 44,013 & 30,332 & 4,502 & 30,698 & 219 \\
\hline & 44.2 & 21.8 & 27.6 & 19.0 & 2.8 & 19.2 & 0.1 \\
\hline \multirow[t]{2}{*}{ RUCC 3} & 64,416 & 33,768 & 43,566 & 29,601 & 5,521 & 30,289 & 229 \\
\hline & 42.6 & 22.3 & 27.8 & 18.9 & 3.5 & 19.4 & 0.2 \\
\hline \multirow[t]{2}{*}{ RUCC 4} & 26,458 & 14,267 & 17,841 & 12,247 & 2,480 & 11,930 & 83 \\
\hline & 41.4 & 22.3 & 27.1 & 18.6 & 3.8 & 18.1 & 0.1 \\
\hline \multirow[t]{2}{*}{ RUCC 5} & 26,696 & 13,554 & 16,226 & 11,497 & 2,602 & 9,952 & 102 \\
\hline & 44.0 & 22.3 & 25.9 & 18.4 & 4.2 & 15.9 & 0.2 \\
\hline \multirow[t]{2}{*}{ RUCC 6} & 18,424 & 9,321 & 11,037 & 7,697 & 1,888 & 6,791 & 69 \\
\hline & 51.7 & 23.1 & 26.3 & 17.3 & 5.6 & 16.9 & 0.5 \\
\hline \multicolumn{8}{|c|}{ Chronic Hypertension } \\
\hline \multirow[t]{2}{*}{ RUCC 1} & 25,760 & 12,594 & 16,750 & 11,233 & 2,121 & 12,397 & 156 \\
\hline & 48.8 & 23.9 & 30.9 & 20.7 & 3.9 & 22.9 & 0.3 \\
\hline \multirow[t]{2}{*}{ RUCC 2} & 20,890 & 9,131 & 11,952 & 7,834 & 1,479 & 8,691 & 122 \\
\hline & 50.6 & 22.1 & 28.1 & 18.4 & 3.5 & 20.4 & 0.3 \\
\hline \multirow[t]{2}{*}{ RUCC 3} & 21,436 & 9,877 & 12,486 & 8,292 & 1,960 & 8,925 & 154 \\
\hline & 49.6 & 22.9 & 28.2 & 18.7 & 4.4 & 20.1 & 0.4 \\
\hline \multirow[t]{2}{*}{ RUCC 4} & 9,228 & 4,113 & 5,171 & 3,377 & 804 & 3,628 & 47 \\
\hline & 50.2 & 22.4 & 27.4 & 17.9 & 4.3 & 19.2 & 0.3 \\
\hline \multirow[t]{2}{*}{ RUCC 5} & 9,026 & 3,922 & 4,688 & 3,170 & 922 & 2,992 & 52 \\
\hline & 51.7 & 22.4 & 26.2 & 17.7 & 5.2 & 16.7 & 0.3 \\
\hline \multirow[t]{2}{*}{ RUCC 6} & 6,515 & 2,910 & 3,392 & 2,221 & 725 & 2,180 & 59 \\
\hline & 51.7 & 23.1 & 26.3 & 17.3 & 5.6 & 16.9 & 0.5 \\
\hline \multicolumn{8}{|c|}{ I/ data presented as N, \% } \\
\hline \multicolumn{8}{|c|}{$\begin{array}{l}\text { Definitions: } \\
\text { RUCC } 1 \text { - county with a large central metropolitan area with a mean statistical area (MSA) population } 1 \text { million or more } \\
\text { individuals } \\
\text { RUCC } 2 \text { - county with a large fringe metropolitan area with a MSA population of } 1 \text { million or more individuals } \\
\text { RUCC } 3 \text { - county with a medium metropolitan area with a MSA population of } 250,000-999,999 \text { individuals } \\
\text { RUCC } 4 \text { - county with a small metropolitan area with a MSA population of less than } 250,000 \text { individuals }\end{array}$} \\
\hline
\end{tabular}


RUCC 5 - county with a micropolitan area with an urban cluster population of 10,000 - 49,999 individuals

RUCC 6 - county with a noncore area with either no urban cluster or an urban cluster population of 9,999 or fewer individuals

Preterm delivery - gestational age at delivery less than 37 weeks and 0 days

Low birth weight - delivery weight less than $2500 \mathrm{~g}$, regardless of gestational age at birth

\section{Table S3. Prevalence of Hypertension in Pregnancy Sensitivity Analysis}

\begin{tabular}{|c|c|c|c|c|c|c|}
\hline & \multirow{2}{*}{\multicolumn{2}{|c|}{$\begin{array}{c}\text { Non-Metro } \\
n=1,525,851\end{array}$}} & \multirow{2}{*}{\multicolumn{2}{|c|}{$\begin{aligned} & \text { Metro } \\
n= & 9,749,529\end{aligned}$}} & \multicolumn{2}{|c|}{$\begin{array}{l}\text { Difference from } \\
\text { Main Analysis }\end{array}$} \\
\hline & & & & & \multirow{2}{*}{$\begin{array}{c}\text { Non-Metro } \\
\% \\
\end{array}$} & \multirow{2}{*}{$\begin{array}{c}\text { Metro } \\
\% \\
\end{array}$} \\
\hline & $\mathrm{n}$ & $\%$ & $\mathrm{n}$ & $\%$ & & \\
\hline \multirow{2}{*}{$\begin{array}{l}\text { Any Hypertensive Disorder } \\
\text { of Pregnancy } \\
\text { Gestational hypertension } \\
\text { or pre-eclampsia }\end{array}$} & 110,962 & 7.27 & 637,751 & 6.54 & -0.09 & -0.10 \\
\hline & 106,952 & 7.01 & 617,773 & 6.34 & -0.10 & -0.10 \\
\hline Eclampsia & 4,903 & 0.32 & 24,015 & 0.25 & 0.01 & 0.00 \\
\hline Chronic hypertension & 32,572 & 2.13 & 177,286 & 1.82 & -0.02 & -0.02 \\
\hline
\end{tabular}


Table S4. Prevalence Ratios for Adverse Pregnancy Outcomes Sensitivity Analysis

\begin{tabular}{|c|c|c|c|c|c|c|}
\hline \multicolumn{7}{|c|}{ Any Hypertensive Disorder of Pregnancy } \\
\hline & \multirow[b]{2}{*}{ PR } & \multirow[b]{2}{*}{$95 \% \mathrm{Cl}$} & \multirow[b]{2}{*}{$\mathrm{aPR}^{\dagger}$} & \multirow[b]{2}{*}{$95 \% \mathrm{Cl}$} & \multicolumn{2}{|c|}{$\begin{array}{l}\Delta \text { from Main } \\
\text { Analysis }\end{array}$} \\
\hline & & & & & $\Delta \mathrm{PR}$ & $\Delta \mathrm{aPR}^{\dagger}$ \\
\hline \multicolumn{7}{|c|}{$\begin{array}{l}\text { Adverse Birthing parent } \\
\text { Outcomes }\end{array}$} \\
\hline Cesarean & 1.01 & $1.01-1.02$ & 1.05 & $1.04-1.06$ & 0.00 & 0.01 \\
\hline Preterm§ & 1.00 & $0.99-1.01$ & 1.08 & $1.06-1.09$ & 0.00 & 0.00 \\
\hline \multicolumn{7}{|c|}{$\begin{array}{l}\text { Adverse Neonatal Outcomes } \\
\text { Any Neonatal Adverse }\end{array}$} \\
\hline Outcome & 0.91 & $0.90-0.92$ & 0.98 & $0.97-0.99$ & 0.00 & 0.00 \\
\hline Low birth weight ${ }^{*}$ & 0.93 & $0.92-0.94$ & 1.06 & $1.04-1.08$ & 0.00 & 0.00 \\
\hline APGAR $<7$ at $5 \mathrm{~min}$ & 1.31 & $1.27-1.35$ & 1.33 & $1.29-1.37$ & -0.01 & 0.01 \\
\hline NICU admission & 0.81 & $0.80-0.82$ & 0.86 & $0.84-0.87$ & 0.01 & -0.01 \\
\hline Neonatal death & 1.09 & $0.94-1.26$ & 1.27 & $1.09-1.47$ & -0.09 & 0.09 \\
\hline \multicolumn{7}{|c|}{ Chronic Hypertension } \\
\hline & & & & & \multicolumn{2}{|c|}{$\begin{array}{l}\Delta \text { from Main } \\
\text { Analysis }\end{array}$} \\
\hline & PR & $95 \% \mathrm{Cl}$ & $\mathrm{aPR}^{\dagger}$ & $95 \% \mathrm{Cl}$ & $\Delta \mathrm{PR}$ & $\Delta \mathrm{aPR}^{\dagger}$ \\
\hline \multicolumn{7}{|c|}{$\begin{array}{l}\text { Adverse Birthing parent } \\
\text { Outcomes }\end{array}$} \\
\hline Cesarean & 1.04 & $1.03-1.05$ & 1.05 & $1.04-1.06$ & 0.00 & 0.00 \\
\hline Preterm $§$ & 0.98 & $0.96-1.01$ & 1.06 & $1.03-1.08$ & 0.01 & 0.00 \\
\hline \multicolumn{7}{|c|}{$\begin{array}{l}\text { Adverse Neonatal Outcomes } \\
\text { Any Neonatal Adverse }\end{array}$} \\
\hline Outcome & 0.90 & $0.89-0.92$ & 0.96 & $0.94-0.97$ & 0.01 & 0.00 \\
\hline Low birth weight ${ }^{*}$ & 0.91 & $0.89-0.93$ & 1.02 & $1.00-1.05$ & 0.00 & 0.00 \\
\hline APGAR $<7$ at $5 \mathrm{~min}$ & 1.31 & $1.25-1.38$ & 1.35 & $1.28-1.42$ & 0.04 & -0.02 \\
\hline NICU admission & 0.80 & $0.78-0.82$ & 0.83 & $0.81-0.85$ & 0.00 & 0.00 \\
\hline Neonatal death & 1.04 & $0.88-1.24$ & 1.23 & $1.03-1.46$ & 0.16 & -0.09 \\
\hline \multicolumn{7}{|c|}{$\begin{array}{l}\text { Metropolitan births is the reference group } \\
\text { tadjusted for birthing parent age, pre-pregnancy BMI, birthing parent race/ethnicity, smoker } \\
\text { before or during pregnancy, and insurance type } \\
\text { Gestational age at delivery }<37 \text { weeks and } 0 \text { days }\end{array}$} \\
\hline
\end{tabular}




\section{BIBLIOGRAPHY}

1. Fingar KR, Mabry-Hernandez I, Ngo-Metzger Q, Wolff T, Steiner CA, Elixhauser A. Delivery hospitalizations involving preeclampsia and eclampsia, 2005-2014. HCUP Statistical Brief \#222. April 2017. Agency for Healthcare Research and Quality, Rockville, MD. Accessed from https://www.hcupus.ahrq.gov/reports/statbriefs/sb222-Preeclampsia-Eclampsia-DeliveryTrends.jsp on July 9, 2020.

2. Gestational Hypertension and Preeclampsia: ACOG Practice Bulletin, Number 222. Obstet Gynecol. Jun 2020;135(6):e237-e260.

3. Say L, Chou D, Gemmill A, et al. Global causes of maternal death: a WHO systematic analysis. Lancet Glob Health. Jun 2014;2(6):e323-333.

4. Report of the National High Blood Pressure Education Program Working Group on High Blood Pressure in Pregnancy. Am J Obstet Gynecol. Jul 2000;183(1):S1S22.

5. Kuklina EV, Ayala C, Callaghan WM. Hypertensive disorders and severe obstetric morbidity in the United States. Obstet Gynecol. Jun 2009;113(6):1299-1306.

6. Doherty A, McLaughlin K, Kingdom JC. Hemodynamic Complications in Pregnancy: Preeclampsia and Beyond. Clin Perinatol. Sep 2020;47(3):653-670.

7. Mammaro A, Carrara S, Cavaliere A, et al. Hypertensive disorders of pregnancy. $J$ Prenat Med. Jan 2009;3(1):1-5.

8. Longo S, Bollani L, Decembrino L, Di Comite A, Angelini M, Stronati M. Shortterm and long-term sequelae in intrauterine growth retardation (IUGR). J Matern Fetal Neonatal Med. Feb 2013;26(3):222-225.

9. U.S. Department of Health and Human Services HRaSA, Maternal and Child Health Bureau. Women's Health 2013. http://mchb.hrsa.gov/whusa13. .

10. Kevin J. Bennett P, John E. Lopes Jr., DHSc, PA-C, Kathleen Spencer, MS, MLS, Saskia van Hecke, BSc. Rural Women's Health: National Rural Health Association; 2013.

11. ACOG Committee Opinion No. 586: Health disparities in rural women. Obstet Gynecol. Feb 2014;123(2 Pt 1):384-388.

12. Hamlin L. Obstetric Access and the Community Health Imperative for Rural Women. Fam Community Health. Apr/Jun 2018;41(2):105-110.

13. Tjaden K. Health Disparities between Rural and Urban Women in Minnesota. Minn Med. Oct 2015;98(10):40-43.

14. Hung P KK, Casey M, Henning-Smith C. State Variability in Access to HospitalBased Obstetric Services in Rural U.S. Counties: University of Minnesota Rural Health Research Center; 2017.

15. Hung $P$, Henning-Smith CE, Casey MM, Kozhimannil KB. Access To Obstetric Services In Rural Counties Still Declining, With 9 Percent Losing Services, 200414. Health Aff (Millwood). Sep 1 2017;36(9):1663-1671. 
16. Hung P KK, Henning-Smith C, Casey M. Closure of hospital obstetric services disproportionately affects less-populated rural counties: University of Minnesota Rural Health Research Center; 2017.

17. Gynecologists AAoPTACoOa. Guidelines for Perinatal Care. In: Kilpatrick SJ MG, Watterbeg KL, ed. 8 ed; 2017.

18. All-County Natality Files (2016-2018). In: Statistics NCfH, ed.

19. U.S. Standard Certificate of Live Birth. Hyattsville, MD; 2003.

20. Statistics NCfH. Guide to Completing the Facility Worksheets for Certificate of Live Birth and Report of Fetal Death. Hyattsville, MD; 2019.

21. Ingram DD FS. 2013 NCHS Urban-Rural Classification Scheme for Counties. Vital Health Statistics. 2014;2(166).

22. Service ER. Rural-Urban Continuum Codes. https://www.ers.usda.gov/dataproducts/rural-urban-continuum-codes.aspx. Accessed January 12, 2021.

23. Bureau USC. Geographic Areas Reference Manual. https://www.census.gov/programs-surveys/geography/guidance/geographicareas-reference-manual.html. Accessed February 24, 2021.

24. American College of $O$, Gynecologists. ACOG Committee opinion no. 548: weight gain during pregnancy. Obstet Gynecol. Jan 2013;121(1):210-212.

25. Coutinho LM, Scazufca M, Menezes PR. Methods for estimating prevalence ratios in cross-sectional studies. Rev Saude Publica. Dec 2008;42(6):992-998.

26. Petersen MR, Deddens JA. A comparison of two methods for estimating prevalence ratios. BMC Med Res Methodol. Feb 28 2008;8:9.

27. Hillemeier MM, Weisman CS, Chase GA, Dyer AM. Individual and community predictors of preterm birth and low birthweight along the rural-urban continuum in central Pennsylvania. J Rural Health. Winter 2007;23(1):42-48.

28. Hutcheon JA, Lisonkova S, Joseph KS. Epidemiology of pre-eclampsia and the other hypertensive disorders of pregnancy. Best Pract Res Clin Obstet Gynaecol. Aug 2011;25(4):391-403.

29. Williams Obstetrics. In: Cunningham FG LK, Bloom SL, Hauth JC, Rouse DJ, Spong CY, ed. 23 ed: McGraw Hill Medical; 2010.

30. Klemmensen AK, Olsen SF, Wengel CM, Tabor A. Diagnostic criteria and reporting procedures for pre-eclampsia: a national survey among obstetrical departments in Denmark. Eur J Obstet Gynecol Reprod Biol. Nov 1 2005;123(1):41-45.

31. Wallis $A B$, Saftlas AF, Hsia J, Atrash HK. Secular trends in the rates of preeclampsia, eclampsia, and gestational hypertension, United States, 19872004. Am J Hypertens. May 2008;21(5):521-526.

32. Cameron NA, Molsberry R, Pierce JB, et al. Pre-Pregnancy Hypertension Among Women in Rural and Urban Areas of the United States. J Am Coll Cardiol. Dec 1 2020;76(22):2611-2619.

33. Prevention CfDCa. Data on Selective Pregnancy Complications in the United States: Hypertensive Disorders, 1993-2014. February 28, 2019; 
https://www.cdc.gov/reproductivehealth/maternalinfanthealth/pregnancycomplications-data.htm\#hyper. Accessed April 2, 2021.

34. Kozhimannil KB, Hung P, Henning-Smith C, Casey MM, Prasad S. Association Between Loss of Hospital-Based Obstetric Services and Birth Outcomes in Rural Counties in the United States. Jama. Mar 27 2018;319(12):1239-1247.

35. Lowery C, Bronstein J, McGhee J, Ott R, Reece EA, Mays GP. ANGELS and University of Arkansas for Medical Sciences paradigm for distant obstetrical care delivery. Am J Obstet Gynecol. Jun 2007;196(6):534 e531-539.

36. Committee Opinion No. 644: The Apgar Score. Obstet Gynecol. Oct 2015;126(4):e52-e55. 